\title{
Electromechanical Properties of Superconductors for DOE/OFE Applications
}

Final Report

Interagency Agreement DE-AI03-93ER54208

\author{
J. W. Ekin and S. L. Bray \\ Electromechanical Technology Division \\ Electronics and Electrical Engineering Laboratory \\ National Institute of Standards and Technology \\ Boulder, Colorado 80303
}

DOE/ER/54208--T/

In many superconductor applications, especially large magnets, the superconductor is required to perform while under the influence of strong mechanical forces. These forces are commonly due to residual fabrication stress, differential thermal contraction of dissimilar materials, and electromagnetic forces generated within an energized magnet coil. Thorough knowledge of a superconductor's electrical performance under the influence of these forces (electromechanical properties) is required for successful magnet engineering. This report presents results of research conducted during the period from August 1993 through March 1997 on the electromechanical properties of superconductors for DOE/OFE fusion applications under interagency agreement DE-AI03-93ER54208. The majority of the research results are contained in three publications that are included in this report. Also, two incremental progress reports, one from Nov. 1994 and one from Nov. 1995, which describe additional results beyond those contained in the publications are also included. 


\section{DISCLAIMER}

This report was prepared as an account of work sponsored by an agency of the United States Government. Neither the United States Government nor any agency thereof, nor any of their employees, makes any warranty, express or implied, or assumes any legal liability or responsibility for the accuracy, completeness, or usefulness of any information, apparatus, product, or process disclosed, or represents that its use would not infringe privately owned rights. Reference herein to any specific commercial product, process, or service by trade name, trademark, manufacturer, or otherwise does not necessarily constitute or imply its endorsement, recommendation, or favoring by the United States Government or any agency thereof. The views and opinions of authors expressed herein do not necessarily state or reflect those of the United States Government or any agency thereof. 


\section{DISCLAIMER}

Portions of this document may be illegible electronic image products. Images are produced from the best available original document. 


\section{Executive Summary}

Our first publication of research results under this interagency agreement, Characterization of Multifilamentary $\mathrm{Nb}_{3} \mathrm{Sn}$ Superconducting Wires for Use in the 45-T Hybrid Magnet, was a collaborative effort with researchers at the National High Magnetic Field Laboratory (NHMFL) and Teledyne Wah Chang. The paper describes the results of characterization studies of candidate $\mathrm{Nb}_{3} \mathrm{Sn}$ superconductors for a $45 \mathrm{~T}$ hybrid magnet being constructed at NHMFL. When completed, this research magnet will generate the world's highest steady state magnetic field and as a by product, extremely high electromagnetic forces within the coil. Our measurements of the effect of axial tensile strain on the critical current of the candidate conductor at $4 \mathrm{~K}$ and $12 \mathrm{~T}$ provided the basic empirical data necessary to model the magnet's performance.

A second publication, High Compressive Axial Strain Effect on the Critical Current and Field of $\mathrm{Nb}_{3} \mathrm{Sn}$ Superconductor Wire, was motivated by the need to model the electromechanical properties of superconductors used in large stainless-steel reinforced magnets, ITER for example, where the relatively high thermal contraction of the steel can place the superconductor under an axial compressive strain of about $-1 \%$. In this study, the axial strain characteristic of a $\mathrm{Nb}_{3} \mathrm{Sn}$ superconductor with a high matrix-to-superconductor ratio was tested. The large matrix volume of this wire places the superconductor under an initial compressive prestrain of approximately $0.95 \%$ at $4 \mathrm{~K}$. Measuring the effect of applied tensile strain on the critical current of the precompressed wire provides data over a wide strain range including high compression. A comparison of the resulting data with the Strain Scaling Law developed at NIST showed that this empirical relation can accurately model $\mathrm{Nb}_{3} \mathrm{Sn}$ strain effects at high levels of compressive strain.

In the final publication, Tensile Measurements of the Modulus of Elasticity of $\mathrm{Nb}_{3} \mathrm{Sn}$ at Room Temperature and $4 \mathrm{~K}$, the stress-strain characteristics of several $\mathrm{Nb}_{3} \mathrm{Sn}$

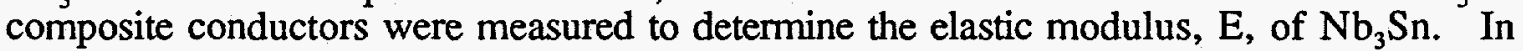
modeling $\mathrm{Nb}_{3} \mathrm{Sn}$ superconductor systems, $\mathrm{E}$ is a key parameter, however, there are large discrepancies in the available data and, prior to this study, there were no published tensiletest measurements of $\mathrm{E}$ for $\mathrm{Nb}_{3} \mathrm{Sn}$ at low temperature. This study showed that $\mathrm{E}$ decreases with decreasing temperature and that its value at $4 \mathrm{~K}$ is approximately $65 \mathrm{GPa}$, compared with $4 \mathrm{~K}$ values more than twice this high that have commonly been used for $\mathrm{Nb}_{3} \mathrm{Sn}$. We subsequently used these results for comparative modeling studies of axial and transverse stress effects in $\mathrm{Nb}_{3} \mathrm{Sn}$.

The two incremental progress reports describe additional results of the program including numerous strain characterizations of ITER and TPX candidate conductors; consultations with DOE laboratories and wire manufacturers on strain effects; a comparative study of axial/transverse stress effects in a $\mathrm{Nb}_{3} \mathrm{Sn}$ monofilament conductor aimed at extending the Strain Scaling Law from one to three dimensions; and a collaborative study with Intermagnetics General Corp. on the combined effects of reactionmandrel material and prereaction annealing of $\mathrm{Nb}_{3} \mathrm{Sn}$ on critical-current-versus-strain characteristics.

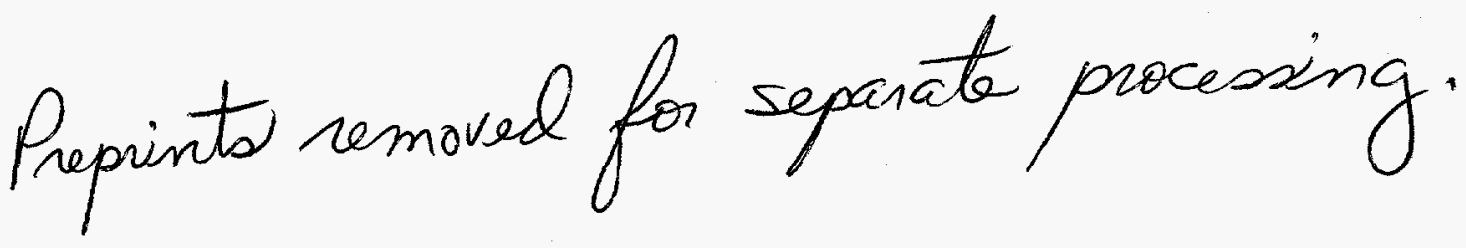




\title{
Tensile Measurements of the Modulus of Elasticity of $\mathrm{Nb}_{3} \mathrm{Sn}$ at Room Temperature and $4 \mathrm{~K}$
}

\author{
S. L. Bray and J. W. Ekin \\ National Institute of Standards and Technology, Boulder, CO USA \\ R. Sesselmann \\ University of Colorado, Boulder, CO USA
}

\begin{abstract}
The critical current of $\mathrm{Nb}_{3} \mathrm{Sn}$ superconductors is highly sensitive to strain. Consequently, accurate mechanical modeling of these conductors is necessary to interpret experimental data and to predict conductor performance in applications such as large magnet systems. A key parameter in these models is the modulus of elasticity (E, Young's modulus); however, there are large discrepancies in the available data, and there are no published tensile-test data on $\mathbf{E}$ for $\mathrm{Nb}_{3} \mathrm{Sn}$. Tensile test specimens were prepared from a starting material of $N b$ tape with $1.4 \mathrm{wt} \% \mathrm{ZrO}_{2}$ precipitates. Tensile measurements of unreacted $\mathrm{Nb}$ and partially reacted $\mathrm{Nb}$ $\mathrm{Nb}_{3} \mathrm{Sn}$ tapes were made at room temperature $(293 \mathrm{~K})$ and at $4 \mathrm{~K}$. A modulus of elasticity of $65 \pm 15 \mathrm{GPa}$ was extrapolated from these measurements for poly crystalline $\mathrm{Nb}_{3} \mathrm{Sn}$ at $4 \mathrm{~K}$, and $150 \pm 15 \mathrm{GPa}$ at room temperature.
\end{abstract}

\section{INTRODUCTION}

$\mathrm{Nb}_{3} \mathrm{Sn}$ is presently the most common superconductor used in magnetic-field applications above $10 \mathrm{~T}$; below $10 \mathrm{~T}, \mathrm{Nb}-\mathrm{Ti}$ dominates. Unlike $\mathrm{Nb}-\mathrm{Ti}$, however, which is ductile at room temperature and relatively insensitive to strain, $\mathrm{Nb}_{3} \mathrm{Sn}$ is britthe and its critical current $\left(I_{c}\right)$ at high magnetic fields is extremely sensitive to strain [1]. In magnet applications of composite $\mathrm{Nb}_{3} \mathrm{Sn}$ conductors, sources of strain may include coil fabrication, differential thermal expansion between the superconductor and the conductor matrix as well as the magnet structure, and the magnetic forces generated within the energized coil.

The magnetic forces in a solenoid magnet produce orthogonal stress components in the conductor, axial tensile stress and transverse compressive stress. The effects of both stress components on the $I_{c}$ of $\mathrm{Nb}_{3} \mathrm{Sn}$ are well documented [1]-[4]. A difficulty arises, however, in comparing their relative effects on $I_{c}$. Due to experimental limitations, the independent variable in the axial test is strain, while in the transverse test it is stress [3]. To directly compare the two effects, the strain data must be converted to stress, or stress to strain, which requires the modulus of elasticity ( $E$, Young's modulus) of $\mathrm{Nb}_{3} \mathrm{Sn}$ at $4 \mathrm{~K}$. Also, the modulus of elasticity is important to

Manuscript received August 27, 1996.

Publication of NIST, not subject to copyright.

This work was supported in part by the U.S. DOE.
$\mathrm{Nb}_{3} \mathrm{Sn}$ magnet designers for modeling the mechanical and electrical responses of the conductor to the various sources of stress.

Numerous data have been reported on $\mathrm{E}$ of $\mathrm{Nb}_{3} \mathrm{Sn}$ at various temperatures including $4 \mathrm{~K} \mathrm{[5]-[13].} \mathrm{The} \mathrm{majority} \mathrm{of}$ these data are based on ultrasonic measurement techniques applied to single-crystal and polycrystalline specimens. The results of vibrating-reed measurements and static beam deflection measurements of $\mathrm{Nb}-\mathrm{Nb}_{3} \mathrm{Sn}$ composites have also been reported. Unfortunately, the reported data for $\mathrm{E}$ of $\mathrm{Nb}_{3} \mathrm{Sn}$ at $4 \mathrm{~K}$ ranges from $32 \mathrm{GPa}$ to $165 \mathrm{GPa}$.

In the present study, tensile tests were performed at room temperature $(293 \mathrm{~K})$ and $4 \mathrm{~K}$ on $\mathrm{Nb}$ and $\mathrm{Nb}-\mathrm{Nb}_{3} \mathrm{Sn}$ tapes. The modulus of elasticity of the $\mathrm{Nb}_{3} \mathrm{Sn}$ portion of the composite was then extrapolated from these data at each temperature.

\section{EXPERIMENTAL DETAILS}

\section{A. Tensile-Test Specimens}

Tensile-test specimens of $\mathrm{Nb}, \mathrm{Nb}-1$ wt. \% $\mathrm{Zr}$, low-carbon steel, and partially reacted $\mathrm{Nb}-\mathrm{Nb}_{3} \mathrm{Sn}$ (with $\mathrm{ZrO}_{2}$ precipitates) composites were prepared for this study. In all cases the widths of the specimens are $3.18 \pm 0.07 \mathrm{~mm}$. The specimens were carefully cut to their nominal width by simply using a straight edge and razor blade. This technique resulted in a uniform specimen width, along its length, typically within $\pm 1 \%$ of the mean. The $\mathrm{Nb}_{3} \mathrm{Sn}$ specimens were cut after the reaction heat treatment. The gage lengths of the specimens range from $237 \mathrm{~mm}$ to $266 \mathrm{~mm}$. The thickness of the specimens differ for each material. The $\mathrm{Nb}$ specimens are approximately $0.075 \mathrm{~mm}$ thick, $0.050 \mathrm{~mm}$ for the steel, and $0.025 \mathrm{~mm}$ for the $\mathrm{Nb}-1$ wt. \% $\mathrm{Zr}$ as well as the $\mathrm{Nb}-\mathrm{Nb}_{3} \mathrm{Sn}$ composites.

The $0.025 \mathrm{~mm}$ specimens fall into two categories, knurled and smooth. The knurled materials have a mechanically textured surface to promote adhesion of the liquid $\mathrm{Sn}-10 \mathrm{wt} . \%$ $\mathrm{Cu}$ coating that is applied to the $\mathrm{Nb}$ tape prior to the $\mathrm{Nb}_{3} \mathrm{Sn}$ reaction process [14]. The smooth specimens lack this surface texturing. Although the smooth specimens are inherently superior to the knurled specimens for tensile tests, because of their uniform cross sections, the knurled specimens were also tested because they were available in a variety of $\mathrm{Nb}-\mathrm{to}_{\mathrm{N}} \mathrm{Nb}_{3} \mathrm{Sn}$ ratios, unlike the smooth specimens. The different composite ratios are achieved by varying the reaction time. Pure $\mathrm{Nb}_{3} \mathrm{Sn}$ specimens could be prepared by increasing the reaction time; but, without the ductile $\mathrm{Nb}$ core, the specimens would be too brittle to handle. Initially, all of the $0.025 \mathrm{~mm}$ specimens had a $\mathrm{Sn}-10 \mathrm{wt} . \% \mathrm{Cu}$ surface coating. The coating was removed with a dilute nitric acid solution prior to testing. 
The steel specimens were included in the study as control specimens to confirm the accuracy of the measurement method.

\section{B. Measurement Method}

The ends of the test specimen are soldered to heavy brass grips, and the specimen is then installed in a rigid cryogenic tensile-test apparatus. The apparatus consists of two stainless steel tubes, an outer stationary tube for force reaction and an inner tube for applying tensile load to the specimen. The brass grips are attached to the load tube and the reaction tube with clevises that allow the grips to pivot in the plane of the specimen, which ensures self alignment and uniform loading. The probe is inserted in a liquid-helium dewar and it is externally connected to a servohydraulic actuator, which provides the tensile load. The actuator is equipped with a linear variable differential transformer (LVDT) for strain measurement and a $1300 \mathrm{~N}$ load cell for stress measurement.

The stress-strain characteristic of the specimen is first recorded at room temperature without exceeding its elastic limit. The specimen is then cooled to $4 \mathrm{~K}$ in liquid helium, and the stress-strain characteristic is measured again. The modulus of elasticity is calculated from the slope of the stress-strain characteristic. The slope is measured at low strain, typically $0.01 \% 100.1 \%$, to ensure pure elasticity.

To measure stress in the specimens, their cross-sectional areas must be determined. Moreover, the area of each component of the composite specimens must be measured to determine $\mathrm{E}$ of the $\mathrm{Nb}_{3} \mathrm{Sn}$. After the tensile tests are completed, three samples are cut from the specimen, one from the center and one from each end. The samples are then mounted in epoxy resin and polished for optical microscopic analysis.

The microscopic images are digitized and computer analyzed. The width of each of the three samples is measured, and an average width is calculated. Because many of the specimens are quite thin $(0.025 \mathrm{~mm})$, the surface roughness often limits the precision of the thickness measurements. This is particularly true for the composite specimens where the reaction process increases the roughness. To statistically reduce this problem, 90 width measurements of each specimen are made, 30 for each sample, and an average width is calculated. In the case of the composite specimens, both the total thickness and the $\mathrm{Nb}$-core thickness must be measured to determine the component areas, doubling the number of required measurements. Finally, the average width of the specimen is multiplied by the average thickness to determine the crosssectional area.

The overall uncertainty of the $\mathrm{E}$ measurements is dominated by the area measurements and estimated to be $\pm 10 \%$. In addition to standard instrument calibrations, including the load cell and the LVDT, a control specimen was prepared from commercial low-carbon steel sheet $(0.050 \mathrm{~mm}$ thick) and tested at room temperature. The value of $\mathrm{E}$ was determined to be $210 \mathrm{GPa}$, which is comparable to the published values for this material, 208 to $209 \mathrm{GPa}$.

\section{RESULTS}

The tensile-test results for the smooth specimens are shown in Fig. 1, which is a plot of $\mathrm{E}$ as a function of specimen composition at room temperature $(293 \mathrm{~K})$ and $4 \mathrm{~K}$. The data located on the ordinate are from the unreacted $\mathrm{Nb}-1$ wt.\% $\mathrm{Zr}$ specimens. The remaining data, from the smooth composite specimens, are for a $\mathrm{Nb}_{3} \mathrm{Sn}$ content of approximately $46 \%$.

Focusing first on the unreacted $\mathrm{Nb}-1$ wt.\% $\mathrm{Zr}$ data, Fig. 1 shows a slight increase in $\mathrm{E}$ when the specimen is cooled from $293 \mathrm{~K}(93 \mathrm{GPa})$ to $4 \mathrm{~K}(97 \mathrm{GPa})$. These $\mathrm{E}$ values are approximately $11 \%$ and $13 \%$ lower, respectively, than previously published ultrasonic measurement results for $\mathrm{Nb}$ single crystals [15]. Texturing of the $\mathrm{Nb}$ grains is the probable source of the reduced $E$ values. Fig. 2 is a photomicrograph of a typical cross section from the composite specimens, showing a central $\mathrm{Nb}$ core and $\mathrm{Nb}_{3} \mathrm{Sn}$ layers on each side. The appearance of the core is consistent with texturing in the $\mathrm{Nb}$ grains. In the tensile tests, the orientation of the applied load is perpendicular to the plane of the figure.

The ultimate purpose of the $\mathrm{Nb}$ tensile tests is, of course, to isolate the elastic modulus of the $\mathrm{Nb}_{3} \mathrm{Sn}$ portion of the composite specimens by subtracting the $\mathrm{Nb}$-core contribution. The unreacted $\mathrm{Nb}-1$ wt.\% $\mathrm{Zr}$ specimens, however, are slightly different from the reacted composite's core, which contains $\mathrm{ZrO}_{2}$ precipitates rather than $\mathrm{Zr}$ in solid solution. In either case the effect on $E$ is undoubtedly slight, given the low concentration of additions.

Several specimens of pure $\mathrm{Nb}$ were also measured. The pure $\mathrm{Nb}$ specimens are approximately three times the

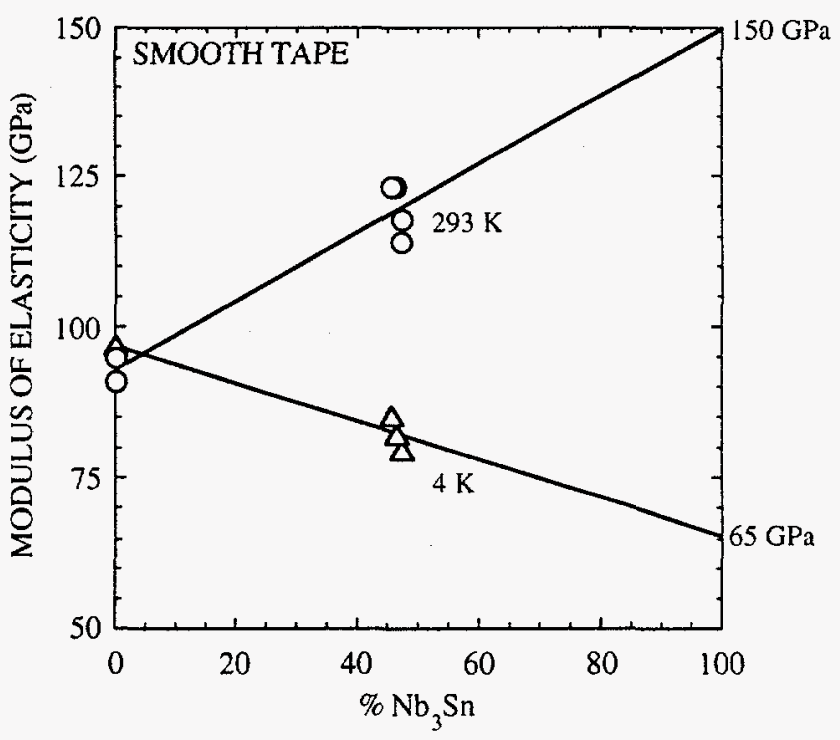

Fig. 1. Modulus of elasticity of smooth specimens at $293 \mathrm{~K}$ and $4 \mathrm{~K}$ as a function of $\mathrm{Nb}_{3} \mathrm{Sn}$ content. Extrapolated values for $100 \% \mathrm{Nb}_{3} \mathrm{Sn}$ are also shown. The polycrystalline $\mathrm{Nb}_{3} \mathrm{Sn}$ contains $1.4 \mathrm{wt} \% \mathrm{ZrO}_{2}$ precipitates (to limit grain growth and enhance flux pinning). 


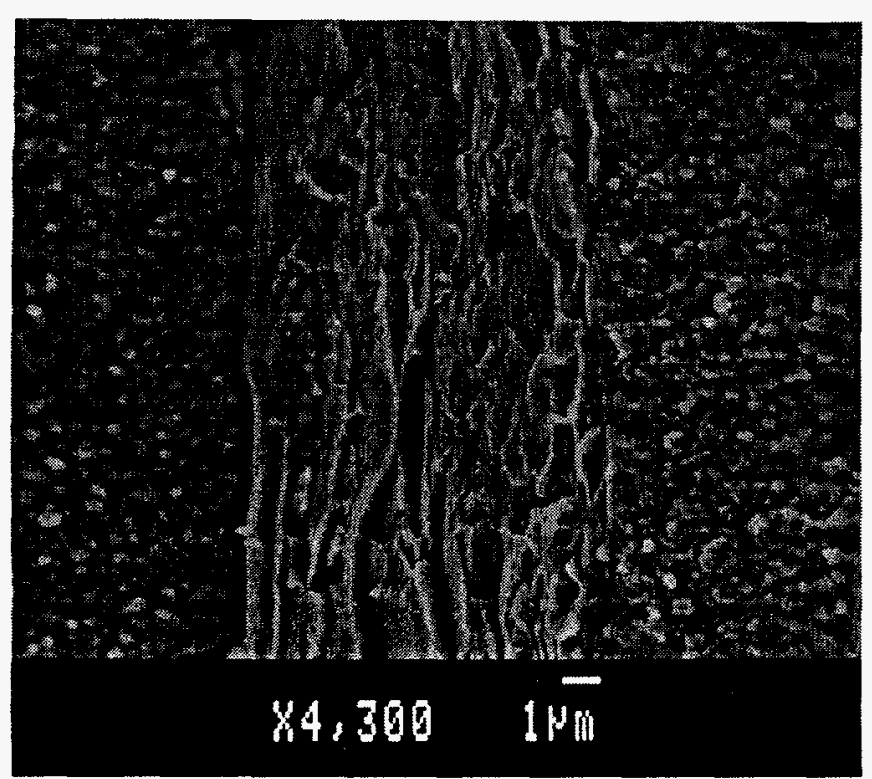

Fig. 2. Cross-sectional photomicrograph of composite specimen, showing central $\mathrm{Nb}$ core and $\mathrm{Nb}_{3} \mathrm{Sn}$ outer layers. In the tensile tests, the orientation of the applied load is perpendicular to the plane of the figure.

thickness of the $\mathrm{Nb}-1 \mathrm{wt} \% \mathrm{Zr}$ specimens, which increases the precision of the cross-sectional area measurements. Consistent with the $\mathrm{Zr}$-alloyed specimens, the measurements of pure $\mathrm{Nb}$ tape produced relatively low $\mathrm{E}$ values, $87 \mathrm{GPa}$ at $293 \mathrm{~K}$ and $94 \mathrm{GPa}$ at $4 \mathrm{~K}$, approximately $15 \%$ below previously published values [15]. Again, texturing is the likely source of the reduced modulus values, and differences in texturing probably account for the relatively small variation in $\mathrm{E}$ between pure $\mathrm{Nb}$ and the $\mathrm{Nb}-1$ wt.\% $\mathrm{Zr}$. The $\mathrm{E}$ values for these textured materials are not indicative of the elastic modulus of nontextured polycrystalline $\mathrm{Nb}$; however, the $\mathrm{Nb}-1$ wt. $\% \mathrm{Zr}$ data are the required values for solving the problem at hand-isolating $\mathrm{E}$ for $\mathrm{Nb}_{3} \mathrm{Sn}$ from the composite data.

Turning to the $46 \% \mathrm{Nb}_{3} \mathrm{Sn}$ composite data, Fig. 1 shows that $\mathrm{E}$ is greater for $\mathrm{Nb}_{3} \mathrm{Sn}$ than for $\mathrm{Nb}$ at room temperature $(293 \mathrm{~K})$. At $4 \mathrm{~K}$ the opposite occurs; $\mathrm{E}$ is lower for the composite, which demonstrates the dramatic softening of $\mathrm{Nb}_{3} \mathrm{Sn}$ at $4 \mathrm{~K}$ [16]. A linear least-squares fit of the data yields extrapolated $\mathrm{Nb}_{3} \mathrm{Sn} \mathrm{E}$ values of $150 \pm 15 \mathrm{GPa}$ at $293 \mathrm{~K}$ and $65 \pm 15 \mathrm{GPa}$ at $4 \mathrm{~K}$. The microstructure of these tapes have been studied in detail [17] using transmission electron microscopy (TEM). TEM analysis of the $\mathrm{Nb}_{3} \mathrm{Sn}$ layers shows that the fine, equiaxed crystals shown in Fig. 2 are randomly oriented. Consequently, the elastic-modulus values for these tapes are indicative of macroscopically isotropic, polycrystalline $\mathrm{Nb}_{3} \mathrm{Sn}$ (with 1.4 wt.\% $\mathrm{ZrO}_{2}$ precipitates).

Fig. 3 is a plot of $\mathrm{E}$ as a function of specimen composition at $293 \mathrm{~K}$ and $4 \mathrm{~K}$ for the knurled specimens. Again, E for the unreacted $\mathrm{Nb}$ is slightly higher at $4 \mathrm{~K}$ than at $293 \mathrm{~K}$, and for the reacted composites it is significantly lower at $4 \mathrm{~K}$, indicating significant low-temperature softening of the $\mathrm{Nb}_{3} \mathrm{Sn}$.
The data in Fig. 3 are plotted on the same scales as the data in Fig. 1 for comparison. The knurling reduces the measured values of $\mathrm{E}$ at both temperatures. This compliance of the knurled specimens is undoubtedly a geometric effect rather than a material property. The knurling creates an undulation along the length of the specimen, which apparently acts like a spring, artificially reducing the measured E value. Consequently, knurled-specimen data are not indicative of intrinsic material properties. The relatively linear relationship between $\mathrm{E}$ and $\mathrm{Nb}_{3} \mathrm{Sn}$ content for the knurled specimens, however, supports the linear extrapolation applied to the smoothspecimen data in Fig. 1.

\section{DisCUSSION}

Ternary additions of $\mathrm{Ta}, \mathrm{Ti}$, and $\mathrm{Zr}$ to $\mathrm{Nb}_{3} \mathrm{Sn}$ have been shown to suppress the martensitic transformation and increase $\mathrm{E}$ at $4 \mathrm{~K}$, in comparison with binary $\mathrm{Nb}_{3} \mathrm{Sn}[10]$. The specimens tested in the present study contain $1 \mathrm{wt} . \% \mathrm{Zr}$, which is oxidized prior to $\mathrm{Nb}_{3} \mathrm{Sn}$ reaction to form $\mathrm{ZrO}_{2}$ precipitates. These precipitates may suppress the martensitic transformation and, thus, they may have a significant effect on $E$.

Ternary additions and precipitates are commonly used in $\mathrm{Nb}_{3} \mathrm{Sn}$ multifilamentary and tape conductors to improve critical-current density and $\mathrm{Nb}_{3} \mathrm{Sn}$ growth kinetics [18]-[20]. Consequently, tensile-test data on these materials are, from an engineering standpoint, as important as data on basic binary $\mathrm{Nb}_{3} \mathrm{Sn}$.

Additional tensile measurements are needed to accurately determine $\mathrm{E}$ for pure $\mathrm{Nb}_{3} \mathrm{Sn}$. Ideally, a series of smooth composite specimens of $\mathrm{Nb}_{3} \mathrm{Sn}$ and $\mathrm{Nb}$, with different $\mathrm{Nb}$-to$\mathrm{Nb}_{3} \mathrm{Sn}$ ratios like the knurled specimens in the present study, need to be tested to determine a more definitive value of $E$ for pure $\mathrm{Nb}_{3} \mathrm{Sn}$.

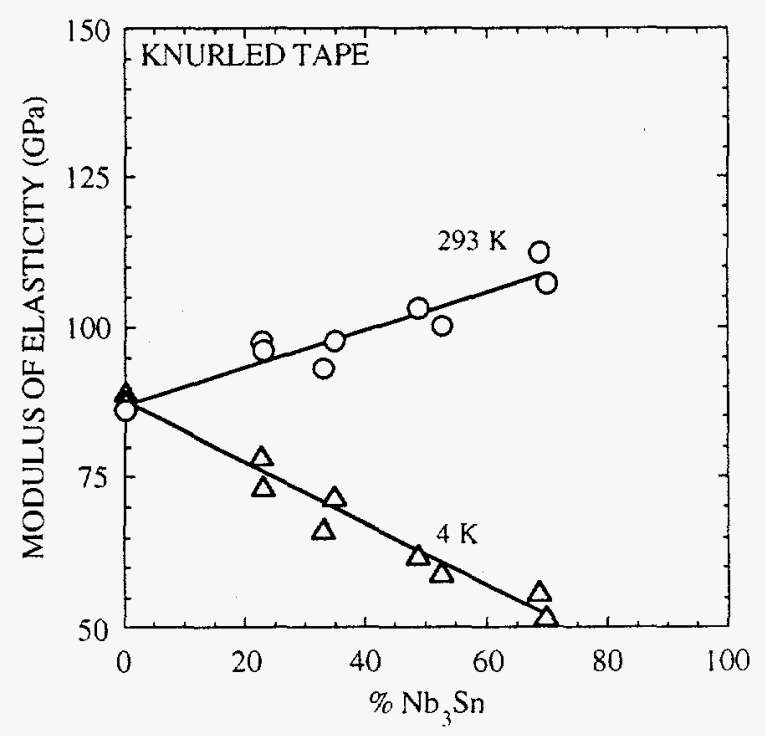

Fig. 3. Modulus of elasticity of knurled specimens at $293 \mathrm{~K}$ and $4 \mathrm{~K}$ as a function of $\mathrm{Nb}_{3} \mathrm{Sn}$ content. 


\section{CONCLUSIONS}

There is a broad range of reported values for the elastic modulus of $\mathrm{Nb}_{3} \mathrm{Sn}$ at $4 \mathrm{~K}$ using various measurement techniques, $32 \mathrm{GPa}$ to $165 \mathrm{GPa}$. The present data are the first published results on the elastic modulus of $\mathrm{Nb}_{3} \mathrm{Sn}$ from tensile tests. These results are qualitatively consistent with most earlier data from ultrasonic, vibrating reed, and static beam deflection measurements, which usually show a lowtemperature softening of the elastic modulus. The results of the present study are summarized in Table I.

TABLE I

ELASTIC-MODULUS VALUES FROM TENSILE TESTS OF POLYCRYSTALLINE $\mathrm{Nb}_{3} \mathrm{Sn}^{\mathrm{a}}$ SPECIMENS

\begin{tabular}{cc}
\hline Temperature & Elastic Modulus \\
\hline $293 \mathrm{~K}$ & $150 \pm 15 \mathrm{GPa}$ \\
$4 \mathrm{~K}$ & $65 \pm 15 \mathrm{GPa}$ \\
\hline
\end{tabular}

${ }^{3}$ The $\mathrm{Nb}_{3} \mathrm{Sn}$ specimens contain $1.4 \mathrm{wt} . \% \mathrm{ZrO}_{2}$ precipitates and are macroscopically isotropic.

\section{ACKNOWLEDGMENT}

The authors thank Christopher G. King of G. E. Medical Systems for preparing the $\mathrm{Nb}_{3} \mathrm{Sn}$ specimens and for many valuable discussions.

\section{REFERENCES}

[1] J.W. Ekin, "Strain scaling law for flux pinning in practical superconductors. Part 1: Basic relationship and application to $\mathrm{Nb}_{3} \mathrm{Sn}$ conductors." Cryogenics, vol. 20, pp. 611-624, November 1980.

[2] G. Rupp, "Stress induced normal-superconducting transition in multifilamentary $\mathrm{Nb}_{3} \mathrm{Sn}$ conductors," IEEE Trans. Magn., vol. 15, pp. 189. 192. January 1979.

[3] J. W. Ekin, "Effect of transverse compressive stress on the critical current and upper critical field of $\mathrm{Nb}_{3} \mathrm{Sn}$," J. Appl. Phys., vol. 62, pp. 4829-4834, December 1987.

[4] W. Specking, W. Goldacker, and R. Flukiger, "Effect of transverse compression on $\mathrm{I}_{c}$ of $\mathrm{Nb}_{3} \mathrm{Sn}$ multifilamentary wire," Adv. Cryog. Eng., vol. 34, pp. 569-575, 1988.
[5] K. R. Keller and J. J. Hanak, "Ultrasonic measurements in single-

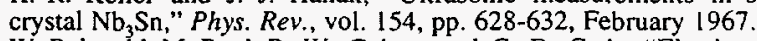

[6] W. Rehwald, M. Rayl, R. W. Cohen, and G. D. Cody, "Elastic moduli and magnetic susceptibility of monocrystalline $\mathrm{Nb}_{3} \mathrm{Sn}$," Phys. Rev. B, vol. 6, pp. 363-371, July 1972.

[7] J. F. Bussiere, D. O. Welch, and M. Suenaga, "Young's modulus of polycrystalline $\mathrm{Nb}_{3} \mathrm{Sn}$ between 4.2 and $300 \mathrm{~K}, " J$. Appl. Phys., vol. 51 . pp. 1024-1030, February 1980.

[8] D. S. Easton, D. M. Kroeger, W. Specking, and C. C. Koch, "A prediction of the stress state in $\mathrm{Nb}_{3} \mathrm{Sn}$ superconducting composites," $J$. Appl. Phys., vol. 51, pp. 2748-2757, May 1980.

[9] Z. P. Chang and G. R. Barsch, "Pressure dependence of elastic constants and of shear mode instability for $\mathrm{Nb}_{3}$ Sn," Phys. Rev. B, vol. 22, pp. $3242-3255$, October 1980

[10] J. F. Bussiere, B. Faucher, C. L. Snead, Jr., and M. Suenaga, "Effects of ternary additions on Young's modulus and the martensitic transformation of $\mathrm{Nb}_{3} \mathrm{Sn}, "$ Adv. Crygo. Eng., vol. 28, pp. 453-460, 1982.

[11] J. F. Bussiere, B. Faucher, and C. L. Snead, "Anomalous elastic softening of polycrystalline $\mathrm{Nb}_{3} \mathrm{Sn}$ below the martensitic transformation temperature," J. Physique Colloq., vol. 43 (C4), pp. 363-368, December 1982.

[12] J. F. Bussiere, H. LeHuy, and B. Faucher, "Elastic behavior of polycrystalline $\mathrm{Nb}_{3} \mathrm{Sn}, \mathrm{V}_{3} \mathrm{Ga}$, and $\mathrm{Nb}_{3} \mathrm{Ge}$," $A d v$. Cryog. Eng., vol. 30, pp. 859-866, 1983 .

[13] M. Poirier, R. Plamondon, and J. D. N. Cheeke, "Elastic constants of polycrystalline $\mathrm{Nb}_{3} \mathrm{Sn}$ between 4.2 and $300 \mathrm{~K}, " J$. Appl. Phys., vol. 55 , pp. 3327-3332, May 1984

[14] N. G. Fiddes, C. G. King, G. S. Kobus, A. Mantone, and F. D. Shaffer, "Apparatus for embossing superconducting tape for use in a superconducting magnet," U. S. Patent \#5379019, January 3, 1995.

[15] K. A. Jones, S. C. Moss, and R. M. Rose, "The effect of small oxygen additions on the elastic constants and low temperature ultrasonic attenuation of Nb single crystals," Acta Met., vol. 17, pp. 365-372, April 1969.

[16] D. O. Welch, "The relationship between the martensitic phase transition and the superconducting properties of A15 compounds," Adv. Cryog. Eng.. vol. 30, pp. 671-682, 1983.

[17] E. L. Hall, M. G. Benz, L. E. Rumaner, and K. D. Jones, "Interface structure, grain morphology, and kinetics of growth of the superconducting intermetallic compound $\mathrm{Nb}_{3} \mathrm{Sn}$ doped with $\mathrm{ZrO}_{2}$ and copper," Mat. Res. Soc. Symp. Proc., vol. 205, pp. 263-268, 1992.

[18] M. Suenaga, K. Aihara, K. Kaiho, and T. S. Luhman, "Superconducting properties of $(\mathrm{Nb}, \mathrm{Ta})_{3} \mathrm{Sn}$ wires fabricated by the bronze process," Adv. Cryog. Eng., vol. 26, pp. 442-450, 1980.

[19] M. Suenaga, S. Okuda, R. Sabatini, K. Itoh, and T. S. Luhman, "Superconducting properties of $(\mathrm{Nb}, \mathrm{Ti})_{2} \mathrm{Sn}$ wires fabricated by the bronze process," Adv. Cryog. Eng., vol. 28, pp. 379-387, 1982.

[20] M. Suenaga, T. S. Luhman, and W. B. Sampson, "Effects of heat treatment and doping with $\mathrm{Zr}$ on the superconducting critical current densities of multifilamentary $\mathrm{Nb}_{3}$ Sn wires," J. Appl. Phys., vol. 45, pp. 4049-4053, September 1974. 
November 3, 1994

Dr. Marvin Cohen, ER-531

U.S. Dept. of Energy

Washington, DC 20585

Dear Marvin,

Enclosed please find the report on accomplishments for FY'94 and a work statement for FY'95.

Testing is coming along fine and, in particular, the preliminary finite element modeling results for $\mathrm{Nb}_{3} \mathrm{Sn}$ are proving to be very interesting. Also, IGC will be sending conductors for us to sort out the reaction mandrel question with a series of electromechanical measurements.

Let me know if you need any more information.

Best wishes,

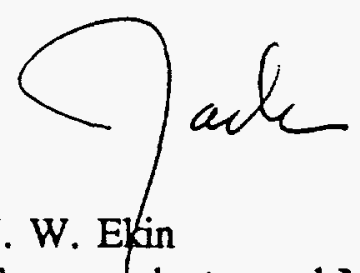

Supercokductor and Magnetic Measurements Group

Electromagnetic Technology Division

Electronics and Electrical Engineering Laboratory

Enclosure 


\title{
Electromechanical Properties of Superconductors for DOE/OFE Applications
}

\author{
Prepared for:
}

U.S. Department of Energy, ER-531

19901 Germantown Road

Washington, DC 20874

Prepared by:

Jack Ekin

Electromagnetic Technology Division

Electronics and Electrical Engineering Laboratory

National Institute of Standards and Technology

Boulder, Colorado 80303

Cost Center 8145529

Report Number 814-5-01

November 1994

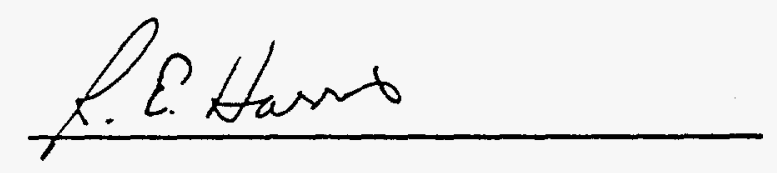

R. E. Harris, Division Chief

Electromagnetic Technology Division

This document has been prepared for the use of the U.S. Dept. of Energy, ER-531, Washington, DC. Responsibility for 1ts further use rests with that agency. However, the report contains descriptions of work which may be incomplete or continuing and is not intended for formal publication. For this reason, NIST requests that if release to the public is contemplated, such action be taken only after consultation with the Program Information office at the National Institute of Standards and Technology, Boulder, Colorado. 


\title{
ELECTROMECHANICAL PROPERTIES OF SUPERCONDUCTORS FOR DOE/OFE APPLICATIONS
}

\author{
Jack Elin \\ National Insititute of Standards and Technology \\ Electromagnetic Technology Div. \\ Boulder, $\mathrm{CO} 80303$
}

\section{DOE/OFE Accomplishment Highlights for FY'94}

* A major report combining several years of electromechanical property data was completed and copies were sent to all participants in the DOE/OFE program. The report contains data on conductors that fall in three general categories: Candidate conductors, experimental conductors, and reference conductors. Candidate $\mathrm{Nb}_{3} \mathrm{Sn}$ superconductors studied include the USDPC cable strand and an ITER candidate conductor. Experimental superconductors included axial strain measurements on a $\mathrm{V}_{3} \mathrm{Ga}$ tape conductor that showed good performance at magnetic fields up to $20 \mathrm{~T}$ and three experimental $\mathrm{Nb}_{3} \mathrm{Sn}$ conductors containing dispersion hardened copper reinforcement for increased tensile strength. Finally, the reference conductors tested were three different $\mathrm{Nb}_{3} \mathrm{Sn}$ conductors from the first and second VAMAS international $\mathrm{Nb}_{3} \mathrm{Sn}$ critical-current round robins. Published papers containing key results were also incorporated into the report, including the first measurement of the transverse stress effect in $\mathrm{Nb}_{3} \mathrm{Sn}$, the effect of stress concentration at cable-strand crossovers, and measurements of the electromechanical properties of $\mathrm{Nb}_{3} \mathrm{Al}$.

* Electromechanical property data were also obtained on a Teledyne Wah Chang $\mathrm{Nb}_{3} \mathrm{Sn}$ candidate superconductor for ITER. The results showed some variability in the critical mechanical parameters (prestrain and irreversible strain) which helps to explain some of the critical current variability observed in the critical current tests of this conductor. The data also served to cross calibrate Teledyne Wah Chang's measurement apparatus and they used the data as part of their technical exhibit at the recent Applied Superconductivity Conference.

* Measurements were also completed of the transverse stress effect and axial stress effect of a monofilament conductor. These data will serve as the basis for finite element modeling of the three-dimensional stress state in $\mathrm{Nb}_{3} \mathrm{Sn}$. A finite element code has been written and we are starting to analyze the results in an attempt to ultimately generate a three-dimensional strain scaling law for use in superconductor magnet engineering. 
* Consultation on critical-current testing and the three dimensional strain state in $\mathrm{Nb}_{3} \mathrm{Sn}$ strand conductors has also been provided to the Princeton Plasma Physics Lab for design of superconductor magnets.

* Consultation on axial strain effects in $\mathrm{Nb}_{3} \mathrm{Sn}$ for use in TPX has also been provided to Lawrence Livermore Lab.

* Consultation on the effects of differential thermal contraction between $\mathrm{Nb}_{3} \mathrm{Sn}$ and the reaction mandrel has also been provided for Intermagnetics General Corp. As a result of these discussions, a series of measurements has been planned of $\mathrm{Nb}_{3} \mathrm{Sn}$ reacted in both the annealed and unannealed states on both stainless steel and Ti-6-Al-4V reaction mandrels. 
Nov. 3, 1995

Dr. Marvin Cohen

U.S. Dept. Of Energy, ER-531

19901 Germantown Rd.

Washington, DC 20874

Dear Marvin,

I enjoyed talking with you in Boston the end of August. As we discussed, I am enclosing with this letter the report of accomplishments for FY'95 and a work statement for FY'96. In light of the discussion on funding at Boston, we have scaled back our budget request to about two-thirds of a staff year, $\$ 150 \mathrm{k}$, from the amount we originally mapped out a couple years ago.

As I mentioned in Boston, testing is coming along fine: we finished four tests on the effect of preannealing the superconductor before winding on the reaction mandrel for IGC, three tests for Mokoto on candidate conductors, and have just been asked by Teledyne Wah Chang to make two tests on their conductors. I am particularly encouraged by some of our recent results on extending the Strain Scaling Law from one to three dimensions and think the deviatoric strain model may prove quite useful in the design of large magnets; we are now working on quantifying the parameters for this design formula.

Let me know if you need any more information.

Best wishes,

Jack 


\title{
ELECTROMECHANICAL PROPERTIES OF SUPERCONDUCTORS FOR DOE/OFE APPLICATIONS
}

\author{
Jack Ekin, Steven Bray, and Norman Bergren \\ National Institute of Standards and Technology \\ Electromagnetic Technology Div. \\ Boulder, $\mathrm{CO} 80303$
}

\section{DOE/OFE Accomplishment Highlights for FY'95}

* Three $\mathrm{Nb}_{3} \mathrm{Sn}$ conductors for the Tokamak Physics Experiment (TPX), two poloidal field (PF) and one toroidal field (TF), were tested. Also, the U.S. ITER candidate conductor, an IGC manufactured $\mathrm{Nb}_{3} \mathrm{Sn}$ wire, was measured as part of the second ITER bench mark testing program. Critical current was measured as a function of axial tensile strain at $12 \mathrm{~T}$. From these data the irreversible strain limit and the intrinsic prestrain were determined.

* In collaboration with Intermagnetics General Corporation (IGC), a series of measurements have been completed on the combined effects of reaction-mandrel material and prereaction annealing on the critical-current vs. strain characteristics of $\mathrm{Nb}_{3} \mathrm{Sn}$ conductors. Four specimens of an IGC conductor were tested; two were reacted on stainless steel mandrels and two on Ti-6-Al-4-V mandrels, which are widely used for reacting and testing ITER candidate conductors. The results show that annealing the conductors in an unconstrained state at $200^{\circ} \mathrm{C}$ for 24 hours, prior to winding the conductor on the reaction mandrel, increases the intrinsic compressive prestrain of the IGC high density conductor from about $0.16 \%$ to $0.20 \%$. This increase would be an advantage in large-magnet applications where the conductor may be subjected to high tensile strain from differential thermal contraction and Lorentz force, thus reducing the risk of taking the conductor into the rapidly decreasing tensile side of the Jc vs. intrinsic strain curve.

* Differential thermal expansion among the components of $\mathrm{Nb}_{3} \mathrm{Sn}$ cable-in-conduit conductors, such as those specified in the ITER design, can cause large axial compressive prestrain of the superconducting filaments. Data contradicting the validity of the Strain Scaling Law for large compressive strain were presented at the 1994 Applied Superconductivity Conference by University of Twente researchers. Subsequently, a $\mathrm{Nb}_{3} \mathrm{Sn}$ monofilamentary wire, with a compressive prestrain greater than $0.9 \%$, was tested by NIST. Results were in very good agreement with the Strain Scaling Law, and they were presented at the 1995 International Cryogenic Materials Conference along with a related review paper on the Strain Scaling Law.

* The Strain Scaling Law has been traditionally used by magnet designers to predict the effect of one dimensional (axial tensile) strain on the critical current of high-field superconductors for fusion applications. Progress is now being made in extending the Strain Scaling Law from one dimension to three dimensions in order to predict the composite effect of multidimensional stresses within the windings of large magnet systems such as ITER. A simple conductor geometry, a multilayer $\mathrm{Nb}_{3} \mathrm{Sn}$ tape, was modeled. Three $\mathrm{Nb}_{3} \mathrm{Sn}$ tape conductors (two custom-made nonknurled tape conductors from General Electric (GE) and one tape conductor from IGC) were also tested under uniaxial tension for eventual comparison with the transverse compression data. A 
preliminary transverse stress test was also run on the GE tape conductor. For the transversecompression case, the stress model predicts an initial increase in critical current, due to a reduction in deviatoric strain, when transverse compressive stress is applied. The transverse test showed this prediction to be at least qualitatively true. This has also been corroborated recently by an independent test at the University of Twente. A quantitative comparison with the deviatoric model is now under way. 